\title{
MUDANÇAS NO JORNALISMO: O REPÓRTER- AMADOR E A ANÁLISE DE REDES SOCIAIS
}

\author{
CHANGES IN JOURNALISM: THE AMATEUR REPORTER AND THE ANALYSIS \\ OF SOCIAL NETWORKS
CAMBIOS EN EL PERIODISMO: EL REPORTERO-AFICIONADO Y EL ANÁLISIS DE REDES SOCIALES

Davi Barboza Cavalcanti'

Sheila Borges de Oliveira ${ }^{2}$

RESUMO: quais são as principais características do repórter-amador e como podemos estudá-lo? Este trabalho, de cunho teórico-metodológico, analisa as mudanças recentes no campo do jornalismo com a passagem do indivíduo da condição de cidadão repórter para a de repórter-amador: atores que produzem notícias a partir de espaços próprios, sem se submeterem a edições e critérios de noticiabilidade do jornalismo. Metodologicamente, fizemos uma discussão sobre as fases do jornalismo para depois enfatizarmos as características do repórter-amador e as técnicas para estudá-lo, a exemplo da Análise de Redes Sociais (ARS) e de entrevistas semiestruturadas. A temática é relevante por contemplar os desafios contemporâneos da comunicação e de pesquisas no ambiente virtual. Entre os resultados, apontamos que, entre outras coisas, o repórter-amador não recebe remuneração, dedica o tempo livre e de lazer a práticas jornalísticas e entra e sai do jornalismo a qualquer momento.

Palavras-chave: Jornalismo. Repórter-amador. Cidadão repórter.

ABSTRACT: what are the main characteristics of the amateur reporter and how can we study him? This theoretical and methodological work analyzes the recent changes

\footnotetext{
ORCID: 0000-0003-1335-1291. E-mail: davi.barboza@hotmail.com

2 ORCID: 0000-0001-8733-7973. E-mail: sheilaborges12@gmail.com
} 
in the field of journalism with the passage from the citizen reporter to the amateur reporter: individuals who produce news from their own spaces, without submitting to journalistic issues and newsworthiness criteria. Methodologically, we will first discuss the phases of journalism and then emphasize the characteristics of the amateur reporter and techniques to study it, such as Social Network Analysis (SNA) and semi-structured interviews. The thematic is relevant to contemplate contemporary challenges of communication and of researches in the virtual environment. Among the results, we point out that, among other things, the amateur reporter receives no remuneration, dedicates his free time and leisure time to journalistic practices, enters and leaves journalism at any moment and has no method of gathering information.

Keywords: Journalism. Reporter-amateur. Citizen reporter.

RESUMEN : Cuáles son las principales características del reportero-aficionado y cómo podemos estudiarlo? Este trabajo, de cuño teórico-metodológico, analiza los cambios recientes en el campo del periodismo con el paso del ciudadano reportero al reportero-aficionado: individuos que producen noticias a partir de espacios propios, sin someterse a ediciones y criterios de noticiabilidad del periodismo. Metodológicamente, primero haremos una discusión sobre las fases del periodismo para despues enfatizar las características del reportero-aficionado y técnicas para estudiarlo, a ejemplo del Análisis de Redes Sociales y de entrevistas semiestructuradas. La temática es relevante por contemplar desafíos contemporáneos de la comunicación y de investigaciones en el ambiente virtual, abordando prácticas periodísticas y motivaciones del ciudadano común. Entre los resultados, señalamos que, entre otras cosas, el reportero-aficionado no recibe remuneración, dedica el tiempo libre y de ocio a prácticas periodísticas y entra y sale del periodismo en cualquier momento.

Palabras clave: Periodismo. Reportero-aficionado. Ciudadano reportero.

\section{Introdução}

O século XXI é a era da sociedade em rede, que mudou profundamente a forma como as pessoas se organizam, mobilizam e comunicam (CASTELLS, 2013). A popularização da internet nos anos 1990 e das redes sociais virtuais no início dos anos 2000, com a enorme capacidade de informar e difundir informações, foram instrumentos chaves para cidadãos comuns serem mais escutados.

A revolução digital mudou radicalmente vários setores da nossa sociedade: a 1) economia, com o e-commerce, marketing digital e big data (ANDERSON, 2006; KOTLER; KARTAJAYA; SERIAWAN, 2017); 2) a comunicação, com a forma das 
pessoas se mobilizarem, a exemplo da Primavera Árabe (Oriente Médio e Norte da África), do Ocuppy Wall Street (EUA), dos Indignados (Espanha) e de outros movimentos antigovernamentais de 2015/2016 (Brasil)3; e (3) o consumo, com novas maneiras de se produzir informações, que é o fio condutor deste trabalho.

Atualmente, parte importante da discussão cívica acontece na internet, não só nas variadas formas do jornalismo online, mas também dentro da vasta rede de internautas e grupos políticos presentes na web. Ferramentas como e-mails, fóruns de discussão, sites, Facebook, Instagram, Youtube, serviços de streaming, Twitter e WhatsApp têm contribuído nesse processo, afetando a forma como as pessoas se informam e se relacionam. Dentro desse contexto, as Novas Tecnologias de Informação e Comunicação4 (NTIC) parecem promover uma "contra-esfera pública" (DONK et al., 2004) que oferece novos caminhos ao que significa ser cidadão.

Chegou-se ao momento oportuno, então, para serem ampliados os estudos dos impactos das novas mídias no jornalismo - verificando como, entre outros fatores, essas tecnologias afetam a elaboração de notícias (quem está produzindo e quais as motivações desses atores?) e o comportamento dos leitores (onde estão se informando? O que buscam e compartilham?).

Para essas reflexões é preciso se levar em consideração as "conquistas" do indivíduo comum, que conseguiu recentemente: a) ter mais acesso às fontes de informação sem precisar necessariamente da mediação da imprensa, b) criar mais alternativas de interação com os conglomerados de comunicação e c) sentir mais motivação para acionar os seus esquemas disposicionais ${ }^{5}$ para criar um espaço próprio de produção de informação. Tais conquistas, facilitadas pela tecnologia digital, fizeram com que algumas pessoas decidissem dar um passo a mais do simples papel de consumidor da informação, tornando-se o que Oliveira (2015) conceitua de repórter-amador.

\footnotetext{
3 Essas mobilizações ocorreram em grande parte devido ao uso de redes virtuais e da internet. Nessas manifestações, as redes sociais desempenharam funções parecidas. O Facebook principalmente na promoção de debates, ações, vídeos e imagens; o Twitter na disseminação em tempo real de informações dos protestos; e o Youtube para o rápido upload e divulgação dos acontecimentos. Atualmente, o WhatsApp também tem importante papel na articulação de pessoas.

4 As NTIC possuem várias definições. Em geral, referem-se a tecnologias que proporcionam comunicação e informação (seja por meio de cabo, fio ou sem fio) no mundo moderno. Neste artigo, as NTIC são entendidas como o conjunto de recursos tecnológicos que proporcionam, por meio das funções de hardware, software e telecomunicações, o funcionamento de processos de comunicação, negócios, pesquisas etc.

5 Na Sociologia, esquema disposicional é o conjunto complexo, individual e intransferível de tendências (disposições) para pensar, sentir e agir que resulta de experiências individuais e, portanto, sociais, vividas por cada ator ao longo de sua trajetória.
} 
Ou seja, aquele cidadão comum, que não tem nenhuma formação especializada em jornalismo, mas decide criar um espaço próprio, geralmente nas redes sociais, para produzir a sua notícia, sem passar pelos tradicionais filtros econômicos e políticos impostos pelos conglomerados de comunicação. Esse indivíduo, para ter a iniciativa de elaborar a própria notícia, já tinha, segundo Oliveira, realizado outros dois movimentos: o de se manter atualizado, consumindo as notícias da grande imprensa, e o de se comunicar com os veículos de comunicação para interagir com os jornalistas, enviando sugestões de pauta ou mesmo imagens e textos que pudessem ser compartilhados com ou sem crédito da autoria, o que Moretzsohn (2007) e Sbarai (2011) conceituam, respectivamente, de repórter-cidadão e correspondente popular. Aqui, adotamos o conceito de repórter-cidadão.

Neste texto, a proposta é a de ressaltar a importância de se aprofundar os estudos relacionados ao universo desses atores que fazem o que Oliveira (2015) chama de agir ativamente no jornalismo. Para Oliveira, o cidadão age ativamente quando realiza três movimentos: 1) o de consumir a informação, o exercício da audiência passiva; 2) o de interagir com a imprensa, desempenhando o papel de cidadão-repórter e participando do processo de produção da notícia como coprodutor da informação; e 3) o de repórter-amador, instituindo o próprio espaço para produzir e divulgar informações a partir de seus critérios sobre 0 que, para ele, é ou não relevante para ser noticiado.

O cidadão age ativamente quando entre e sai do campo do jornalismo ao interagir com os profissionais especialistas, àqueles que dominam os valores do campo e disputam um lugar nesse espaço para serem reconhecidos como membros dele. $O$ ator é cidadão-repórter quando interage e é repórter-amador quando deixa esse jogo de entrada e saída do campo para criar um espaço próprio, fora dele, para escrever a sua notícia.

Para responder à pergunta aqui proposta, "quais as principais características do repórter-amador e como podemos estudá-lo?", este artigo está organizado da seguinte maneira: 1) fases do jornalismo; 2) sociedade em rede e práticas jornalísticas do cidadão comum, 3) motivações e estudo do repórter-amador e 4) considerações finais.

\section{Fases do jornalismo: do opinativo ao tecnológico}

Para Marcondes Filho (2002), o jornalismo tem quatro fases: a opinativa, a informativa, a explicativa e a tecnológica. Essas etapas mostram como o jornalismo foi sendo reconhecido como um campo social que faz a mediação entre 
o indivíduo e outras áreas. Delegou-se ao jornalismo a missão de entrar em lugares aos quais o ator não tinha acesso para que pudesse tomar conhecimento de fatos que poderiam ser do interesse da sociedade. Assim, o jornalismo foi conquistando uma centralidade, um lugar de referência na construção social da realidade (VIZEU, 2009; VIZEU; ROCHA; MESQUITA, 2011).

De acordo com Marcondes Filho (2002), a primeira fase do jornalismo vai de 1789 a 1830. É a época do jornalismo político-literário exercido sem fins econômicos e do jornalismo opinativo. Nesse início, o jornalismo, segundo Lima Sobrinho (1988), era uma atividade cultivada por indivíduos idealistas, liberais e até românticos que acreditavam nos ideais da Revolução Francesa. É o jornalismo impresso exercido de forma artesanal, feito pelo cidadão que desejava debater ideias. Assim, contribuía para jogar luz na escuridão, esclarecendo sem esconder o viés opinativo. $\mathrm{Na}$ sociedade brasileira, naquela época, o jornalismo era uma atividade exercida de forma voluntária e engajada por cidadãos de qualquer área profissional que queriam dar visibilidade às propostas de seus grupos econômicos, políticos e culturais.

Esse cidadão que praticava o jornalismo em seus primórdios reaparece no final do século XX exercendo o papel de repórter-amador. Naquela fase, escrevia de forma artesanal e voluntária nas gráficas improvisadas nas casas e nos locais de trabalho. Hoje, basta ter um smartphone conectado à internet para produzir notícias e divulgá-las nas plataformas digitais. De uma forma ou de outra, o indivíduo busca dar visibilidade a temas que muitas vezes estão fora da pauta da agenda pública, definida por pessoas que detêm poder e pela grande imprensa.

De acordo com a pesquisa doutoral, realizada por Oliveira (2015), os repórteres-amadores não exercem a atividade de produzir notícia como a principal forma de ganhar a vida. Escrevem notícia no tempo livre e de forma voluntária em espaços criados por eles, principalmente nas redes sociais. Nessa ação, acionam as disposições sociais que os fazem desempenhar os papéis de autores das próprias notícias. Assim, impactam o campo do jornalismo, pois escrevem informações que antes ficavam escondidas de parte da audiência ao ficarem retidas nos filtros impostos pelos donos dos conglomerados de comunicação. Quando a sociedade não tinha acesso às redes sociais e aos sites de instituições sociais, ficava refém das notícias divulgadas exclusivamente pela grande imprensa.

A segunda fase, a do jornalismo informativo, foi de 1830 a 1900 . Entre os fatores que contribuíram para essa etapa podem ser citados a alfabetização da população, a urbanização das cidades, a criação de empresas jornalísticas e o progresso tecnológico. O jornal passa a ser visto como uma empresa, assim como qualquer outra do sistema capitalista. Nessa etapa, surgiram novos gêneros 
jornalísticos, como a entrevista e a reportagem, e os jornais se tornaram mais acessíveis, com a linguagem tendo de ser clara, concisa, direta, simples e precisa.

O jornalismo mais engajado e opinativo foi paulatinamente sendo substituído pelo modelo que conhecemos atualmente, que privilegia os interesses das empresas de comunicação. As gráficas manuais e artesanais foram dando lugar às rotativas, que produziam em escala industrial. Abriu-se espaço para os anúncios e as matérias pagas. $O$ jornal tinha que almejar o lucro para pagar os custos de investimentos da modernização do parque gráfico e da contratação de profissionais. Nesse sentido, na primeira fase, mais opinativa, valorizavam-se as ideias e a cultura geral; enquanto na segunda destacavam-se a velocidade e a precisão na apuração e na redação da notícia.

Na segunda metade do século XIX, o modelo de jornalismo norte-americano se dividia entre as notícias sensacionalistas (penny press), principalmente as dos crimes espetaculares, e o lide que respondesse aos $5 \mathrm{~W}_{1} \mathrm{H}^{6}$. A informação sem comentário despertaria mais respeito entre os leitores, o que levou o jornalismo a almejar a neutralidade, combinada com a pretensa objetividade. A objetividade, vale ressaltar, constrói-se dentro dos interesses estabelecidos pelos veículos de comunicação. A intenção é a neutralidade, mas o texto faz parte de uma construção narrativa na qual os argumentos de persuasão não deixam de estar presentes.

É na terceira fase do jornalismo, de 1900 a 1960, que os grandes conglomerados de comunicação se consolidam, formando os monopólios. Os jornais impressos começam a rodar em grandes tiragens e se inicia a etapa do jornalismo de explicação. Esse modelo de análise pressupõe a especialização dos jornalistas, contrapondo-se ao formato generalista e descritivo anterior. No entanto, no final dos anos 1960, voltou-se a valorizar a narrativa mais subjetiva, retomando em parte o texto mais opinativo da fase inicial.

A industrialização da imprensa, contudo, deu origem a um modelo de negócios que suplantou o jornalismo movido à paixão e ao idealismo, exercidos de forma amadora em gráficas quase artesanais. Ao longo dos anos, as empresas foram se fortalecendo e criando sistemas de comunicação que favoreceram o surgimento de conglomerados nos quais um único grupo é responsável pela administração de vários veículos, como jornais, rádios e

\footnotetext{
6 O lide tradicional corresponde ao primeiro parágrafo da reportagem, que precisa ser escrito a partir da informação mais importante, nova ou curiosa. Esse modelo segue o esquema dos $5 W_{1} H$, que vai orientar o repórter a responder: quem ou com quem aconteceu o fato (who), o que aconteceu (what), quando (when), onde (where), por que (why) e como se deu este fato (how).
} 
televisões. Esses conglomerados começaram em escala regional para depois atingirem a nacional (MELO, 2010) e, atualmente, transnacional.

A quarta fase começa nos anos 1970 e vai até os dias de hoje - é a etapa do jornalismo tecnológico. As novas ferramentas da comunicação, criadas com a internet, provocaram mudanças profundas no mundo social, passando do sistema analógico ao digital. O grande avanço ocorreu na década de 1990, quando a potencialidade da comunicação, advinda da grande rede de computadores, começou a ser utilizada como ferramenta para democratizar o acesso dos indivíduos à informação.

Com a entrada do computador nas redações e, posteriormente, o acesso dessas mesmas redações à internet, o jornalismo deu um grande salto, o que provocou uma série de mudanças nas práticas jornalísticas, as quais podem ser divididas, segundo Soster (2009), em três fases. A primeira é marcada justamente pela popularização da internet, o que ocorre a partir da década de 1990. O marco balizador é o surgimento das versões digitais dos jornais impressos, que passam a disponibilizar os seus conteúdos nos sites, mudando a configuração da relação entre jornalistas, empresas e cidadãos comuns.

A segunda fase é caracterizada pela processualidade desse novo cenário que redimensiona o sistema midiático, envolvendo atores, espaços sociais e ferramentas oferecidas pela informatização. Essa relação se estende do interior de um veículo para outro, a exemplo de notícias divulgadas por sites que se transformam em pautas para outros veículos.

A terceira fase é marcada pela descentralização, autorreferência e correferencialidade. Ancorado em uma estrutura de rede, o jornalismo opera a partir de uma nova lógica. O lugar discursivo não está mais centralizado nas redações, desloca-se no fluxo construído por uma sociedade interligada por uma rede. Muitas vezes o acontecimento, segundo Soster (2009), é construído dentro desse fluxo.

As instituições jornalísticas continuam sendo importantes, mas passam a fazer parte de um sistema maior porque, com a internet, o fluxo da informação é multidirecional. Esse sistema é instituído pelas empresas que produzem a notícia em rede, agregando as redações de veículos impressos, radiofônicos, televisivos e digitais, e entrando em parceria com veículos regionais. É neste contexto que surge o nosso cidadão comum que age ativamente, ator disposto a atuar no processo de produção e difusão da informação, dialogando com a grande imprensa e instituindo um espaço próprio de produção da informação.

Soster (2009) chama de autorreferencialidade o fato de as operações jornalísticas se voltarem para o próprio sistema midiático. As fontes estão, cada vez mais, no interior desse sistema. Na correferencialidade, os veículos se referenciam mutua- 
mente. $\mathrm{O}$ acontecimento pode ser gerado dentro do fluxo de informações, quando os veículos interagem entre si. Os sites jornalísticos incorporam outras mídias em seus espaços, exercendo uma cultura de convergência midiática (JENKINS, 2008).

Com as novas tecnologias digitais, o fluxo de informação caminha por vários sentidos (PRIMO, 2011). Ao partir da análise que Jenkins faz de forma global, Primo avalia o cenário brasileiro. Com o tripé da alta definição, interatividade e mobilidade, a tecnologia digital, cujo sinal é composto pelo sistema binário (o ou 1), descontínuo e sem nuances intermediárias, proporcionou: sinais mais eficientes do que na transmissão analógica; interatividade com o leitor/espectador; possibilidade de navegar na internet para efetuar transações; e convergência entre mídias, ou seja, possibilidade de um mesmo conteúdo, ou adaptações dele, ser reproduzido em vários veículos.

Atualmente, a outrora linha que demarcava precisamente o lugar do produtor e do receptor da informação não existe mais, e a indústria do jornalismo sofre mudanças profundas, com dois pontos de vista antagônicos se difundindo. No primeiro, a tecnologia digital e as novas mídias podem ser notadas como vilãs, devastando a forma tradicional da produção audiovisual, impressa e radiofônica. No outro ponto, são vistas como aliadas, oferecendo novas possibilidades de crescimento e melhoramento de atividades existentes.

Independentemente da perspectiva defendida, o que destacamos é o fato de que as empresas de comunicação não são mais detentoras do poder de mediar e controlar a informação. Atualmente, concorrem com blogs, sites, fanpages e tuítes de pessoas comuns sem formação jornalística, cada vez mais presentes nas diversas mídias, principalmente nas digitais e nas redes sociais virtuais. Assim, na era da comunicação tecnológica, o polo de produção foi descentralizado e ampliado, podendo-se buscar informação em qualquer lugar através dos acessos permitidos pela conexão em rede.

\section{A sociedade em rede e as práticas jornalísticas do cidadão comum}

No século XXI, a sociedade globalizada e interconectada em rede foi vital para encurtar distâncias e, especificamente no âmbito da comunicação, viabilizar a existência do repórter-amador. Mas qual o papel das redes nesse processo? Uma rede pode ser interpretada como uma metáfora para se observar padrões de interação entre pessoas e sua inserção em círculos sociais, podendo ser vista a partir de laços entre dois indivíduos, "os atores (pessoas, instituições ou grupos; 
os nós da rede) e as suas conexões (interações ou laços sociais)" (RECUERO, 2009, p. 24). Redes são complexas, instáveis, plásticas e extremamente heterogêneas, com as posições dos indivíduos em uma estrutura reticular dificilmente horizontais.

Pessoas e grupos em rede sempre existiram, vale ressaltar, mas o advento das redes sociais virtuais proporcionou novas possibilidades de comunicação e relacionamento, provocando uma revolução no modo de se buscar e produzir informação. Nesse sentido, a interatividade por meio da internet abriu novas perspectivas para o jornalismo e mudou as relações sociais construídas entre empresa, jornalista e cidadão comum, como explicado anteriormente.

Essa interatividade - que pode ser feita através de hashtags em redes sociais, fóruns de discussão, games e formulários para contato - permite ao indivíduo que tem acesso ao computador e à grande rede estabelecer um diálogo com os veículos de forma mais rápida e transparente, enviando sugestões de matérias, emitindo opiniões sobre o conteúdo das edições e acompanhando os desdobramentos de suas intervenções. Ademais, na internet, esse ator pode ao mesmo tempo acessar bancos de dados, redes sociais ou sites para procurar informações e criar espaços próprios para produzir a própria notícia com base nesses dados. Não precisa mais ficar refém da mediação da grande imprensa.

Para Belochio e Mielniczuck (2011), quando esses sistemas colaborativos, disponibilizados pelos veículos, permitem que o ator participe da etapa de apuração da matéria jornalística, o jornalismo não é só colaborativo, mas passa a outro estágio, chamado por eles de crowdsourcing - termo utilizado para informar à audiência que o indivíduo não está só desempenhando o papel de fonte, mas também o de coprodutor do conteúdo. Por isso, Belochio e Mielniczuck classificam essa etapa do jornalismo open source (fonte aberta), ou seja, quando o texto da matéria jornalística é elaborado de forma compartilhada e distribuído em código aberto (BRIGGS, 2007).

Já Ferrari (2007) e Castro (2011) utilizam o termo "jornalismo cidadão" para dar dois sentidos às novas práticas elaboradas pelos cidadãos comuns. No primeiro sentido, seria usado para definir a relação entre este indivíduo e a empresa por meio da qual o ator poderia se comunicar com a redação para transmitir informações sem intermediário e participar como coprodutor do processo de elaboração da notícia. Por esse ângulo, a noção de jornalismo cidadão seria uma síntese das definições anteriores de jornalismo colaborativo e de fonte aberta.

No segundo sentido, Ferrari (2007) e Castro (2011) argumentam que o termo jornalismo cidadão também é utilizado para definir a iniciativa do indivíduo que procura os veículos de comunicação para fazer denúncias em busca de solução para 
resolver um problema da sociedade. Acolhido ou não pela grande imprensa, esse indivíduo também está criando um espaço próprio de comunicação, na maioria dos casos pela internet. Assim, o jornalismo cidadão está criando a figura do leitor que quer se transformar em repórter, mesmo que de forma amadora. Esse leitor não estava se sentindo contemplado com a informação que era recebida passivamente. Prefere a notícia produzida de forma interativa, publicada na internet, em tempo real.

Independentemente das interpretações de Ferrari (2007) e Castro (2011), o jornalismo é, para Lara ([2009]), essencialmente cidadão. Por isso, Lara afirma que é mais apropriado falar em "cidadãos vinculados a atos jornalísticos" do que em jornalismo cidadão. Todas essas novas práticas do jornalismo, sejam como forem denominadas pelos pesquisadores - colaborativa, fonte aberta, cidadã, participativa ou cívica -, traduzem a inquietação do cidadão comum que não quer mais ficar na posição passiva de consumidor da notícia, principalmente com as facilidades de acesso à informação surgidas com a popularização da internet. Essas mudanças evidenciam a importância de se estudar o mundo desses indivíduos para compreender quais são e como os esquemas disposicionais acionados inconscientemente os levam a querer ser cidadão-repórter e repórter-amador.

\section{Motivações e estudo do repórter-amador}

Para agir ativamente, o cidadão comum tem de acionar o seu esquema disposicional com o objetivo de colaborar e produzir notícia. Assim, o movimento de ação fica completo. Quando age ativamente no jornalismo este indivíduo não é remunerado para ser repórter-amador: as atividades são voluntárias, ligadas ao tempo livre dedicado ao prazer de ler, de se informar, de escrever ou de reivindicar melhores condições de vida para as comunidades.

Por isso, não há uma rotina diária fixa e tempo pré-determinado para executar esses dois movimentos, impulsionados por uma força interna que move inconscientemente o pensar e o agir do repórter-amador. $\mathrm{O}$ tempo dedicado a eles é o de descanso. Isso porque essas práticas não fazem parte das atividades do trabalho remunerado, que é priorizado e para o qual o indivíduo dedica a maior parte do tempo. Daí a designação de amador.

Em função disso, além de não delegarem às práticas jornalísticas um tempo fixo, o ator não se preocupa com a adoção de métodos de trabalho para, por exemplo, apurar a informação e divulgar outras versões da notícia. O cidadão comum que age ativamente no jornalismo tem as características que podemos enumerar no 
Quadro 1. Elas foram elaboradas com base na pesquisa de campo feita por Oliveira (2015) durante um ano, seguindo a metodologia de Lahire (2002; 2004; 2006; 2010).

Para ter acesso às disposições dos indivíduos, é preciso reconstruir as trajetórias de vida deles, resgatando as experiências do passado e do presente nos processos de socialização em diversos mundos sociais, como os da família, da educação, da comunidade e do trabalho. Assim, para ter acesso às trajetórias de vida, Oliveira (2015) fez entrevistas exploratórias e em profundidade com internautas presentes em um fórum colaborativo, buscando identificar características do repórter-amador.

Quadro 1 - As características do repórter-amador

\section{CARACTERÍSTICAS}

Não recebe remuneração para exercer a atividade;

Dedica o tempo livre e de lazer a essas práticas jornalísticas;

Entra e sai do jornalismo a qualquer momento porque não tem compromisso com nenhuma rotina profissional;

Não tem método de apuração de informação;

Não precisa frequentar um curso universitário para ser repórter-amador;

Vincula essas práticas ao gosto de ler, de se informar, de escrever, de denunciar e de reivindicar melhores condições de vida para as comunidades em que vivem;

Não quer se submeter ao controle editorial da empresa de comunicação para que possa ver publicada a notícia que criticou ou sugeriu.

Fonte: Elaborado pelos autores a partir de Oliveira (2015).

São essas características que o diferenciam do jornalista profissional, uma vez que o especialista está dentro de uma organização empresarial com normas e valores que precisam ser seguidos. Em relação ao ator que age ativamente, 0 jornalista profissional tem o perfil que podemos descrever a seguir, no Quadro 2

Quadro 2 - Características do jornalista

\section{CARACTERÍSTICAS}

Recebe remuneração;

Dedica à atividade o seu tempo para o trabalho;

Exerce um papel permanente dentro do campo do jornalismo; 


\begin{tabular}{l}
$\begin{array}{l}\text { Tem uma rotina profissional que precisa ser obedecida: métodos de apuração, de redação e de edição de } \\
\text { informação; }\end{array}$ \\
\hline Vincula esta prática ao exercício profissional e remunerado; \\
\hline Precisa se submeter ao controle editorial dos conglomerados de comunicação para os quais está trabalhando; \\
\hline Precisa frequentar um curso universitário*. \\
\hline $\begin{array}{l}\text { * O exercício profissional vinculado à aquisição de um diploma universitário era um requisito para a prática } \\
\text { da atividade desde a primeira metade da década de } 1960 \text { do século XX. Uma decisão do Supremo Tribunal } \\
\text { Federal, porém, acabou com a regulamentação da profissão em } 2011 \text {. Por iniciativa do Congresso Nacional, esta } \\
\text { regulamentação foi restabelecida, mas até a publicação deste artigo esse debate não tinha sido encerrado. }\end{array}$
\end{tabular}

Fonte: Elaborado pelos autores a partir de Oliveira (2015).

Para agir ativamente no jornalismo, o ator não precisa, necessariamente, exercer essas duas práticas - ser cidadão-repórter e ser repórter-amador - de forma simultânea. Ele pode deflagrá-las em momentos distintos, mas para realizá-las o indivíduo deve acionar o seu esquema disposicional.

De acordo com Lahire (2002; 2004; 2006; 2010), cada indivíduo tem esquemas disposicionais plurais e únicos, que foram sendo construídos inconscientemente ao longo das trajetórias de vida em função de experiências de socialização múltiplas e heterogêneas. As sociedades modernas têm fortes componentes de diferenciações culturais, que são potencializadas com o fluxo de informações compartilhadas por atores que estão interligados em grandes redes virtuais. $\hat{E}$ neste contexto que os núcleos da família e da escola, por exemplo, não detêm mais o controle pela educação do indivíduo.

O nosso conceito do agir ativamente do repórter-amador difere da noção de fonte ativa aplicada por Melo (2003), que atribui essa classificação aos atores e instituições que ocupam uma posição social de destaque e que se tornam, consequentemente, fontes confiáveis para os jornalistas. O agir ativamente também se distingue da noção de fonte participativa de García de Madariaga Miranda (2008) e Mesquita (2010), utilizada para abrigar o indivíduo que é consultado pelos veículos de comunicação, mesmo que esse ator não esteja nos papéis de fonte oficial, oficiosa ou expert (LAGE, 2002; SANTOS, 2003), as mais valorizadas da tradicional narrativa jornalística. 


\section{Algumas reflexões}

O repórter-amador é cada vez mais frequente na sociedade atual, contando, como mencionado, com a ajuda das redes sociais virtuais que proporcionaram aos cidadãos espaços próprios para atuarem, a exemplo de blogs e redes sociais. No Brasil, há inúmeros sites, youtubers, fanpages e blogs conduzidos por pessoas, e algumas vezes até grupos, que se enquadram no conceito de repórter-amador. E um grande desafio para pesquisadores é estudar e analisar esses novos atores do jogo, cujo alcance na opinião pública muitas vezes é até maior do que o da mídia tradicional.

Até mesmo no e-commerce, por exemplo, pesquisas apontam que a opinião de compradores comuns e de influenciadores nas redes virtuais, ou seja, pessoas "normais", são muito mais importantes em uma decisão de compra do que anúncios multimilionários realizados por grandes empresas (KOTLER; KARTAJAYA; SERIAWAN, 2017). Isso porque os internautas se identificam com indivíduos comuns, os quais passam maior credibilidade.

Retomando ao repórter-amador, o desenvolvimento desse sujeito tem alguns desdobramentos no campo do jornalismo. Um ponto positivo, pode-se argumentar, seria uma maior pluralidade da informação, com mais pessoas participando de notícias, inclusive agentes antes invisíveis. Os próprios veículos não podem mais "esconder" informação, pois ela pode ser encontrada mais facilmente pelo cidadão que está nas redes. Porém, tal fato merece duas observações. A primeira é que as redes sociais, instrumentos de divulgação de repórteres-amadores, têm características de rede como centralidade e hubs (atores centrais), ou seja, agentes centrais (como a mídia tradicional) costumam controlar o fluxo de informações, sem haver, nesse caso, a pluralidade e a horizontalidade geralmente atrelada à internet.

Estudos de casos realizados na África, por exemplo, apontam que enquanto as novas mídias têm potencial para ajudar a monitorar e mobilizar a atividade política, também reforçam posições dos que estão no poder. No Zimbábue, nação em grave crise política/econômica que teve um mesmo presidente por 37 anos (até 2017), apesar de existirem sites que denunciem a má governança política e a violação de direitos humanos, o domínio destes fica nas mãos de poucos.

Análise de conteúdo de websites no Zimbábue (MOYO, 2009) apontou que o controle da internet permanece sob o domínio de uma minoria, com o governo e a elite econômica promovendo discursos que giram em torno dos próprios interesses, reproduzindo ideologias dominantes. As NTIC também serviram para

7 Veja reportagem do G1, disponível em: https://g1.globo.com/mundo/noticia/mugabe-renuncia.ghtml. Acesso em: 2 abr. 2018. 
fins "maléficos" em países como o Quênia, sendo utilizadas para a manutenção de grupos dominantes segundo relatórios das principais ONGs do país (Abdi e Dean, citado por MOYO, 2009).

No Brasil, elites políticas tradicionais proprietárias de grandes conglomerados de comunicação também controlam parte significativa do conteúdo lido na internet e orientam as pautas de assuntos virtuais. Segundo matéria de Soares e Sá (FOLHA DE SÃO PAULO, 2013), a produção de jornais, TVs e portais brasileiros dominou os compartilhamentos em redes sociais durante os protestos de junho de 2013.

Entre 6 e 22 de junho, "links da mídia brasileira responderam por $80 \%$ dos endereços de maior alcance nas principais hashtags (palavras-chaves que viram hiperlinks na web) das manifestações do Twitter. Só $5 \%$ eram postagens de blogs", destaca a matéria. No Facebook, o domínio se manteve.

A segunda observação a ser destacada acerca de uma possível "democracia digital" é que o repórter-amador muitas vezes não segue critérios de noticiabilida$\mathrm{de}^{8}$, tampouco de ética, o que faz com que fake news sejam frequentes em digital influencers conhecidos - prática que o Facebook está tentando mitigar. Nesse sentido, chegamos a outro aspecto crucial na nossa discussão: de que maneira podemos estudar os repórteres-amadores e até novos agentes da esfera virtual? Felizmente, o pesquisador contemporâneo interessado tem à disposição várias técnicas, a depender do problema de pesquisa. A seguir mostraremos um caminho, entre tantos, que pode ser seguido: a utilização de métodos mistos através da Análise de Redes Sociais (ARS), ferramentas para captura de dados e entrevistas.

\section{Métodos de pesquisa em rede}

A ARS vem crescendo em várias áreas de conhecimento9. De acordo com Rodríguez (1995), a ARS não é uma técnica mais ou menos sofisticada de análise de fenômenos sociais, mas sim uma nova aproximação teórica. A metodologia da ARS considera a estrutura da relação entre atores e o posicionamento do

\footnotetext{
8 Um acontecimento vira notícia pelo seu valor informativo, que indica a relevância. Os valores-notícia são um dos principais componentes da narrativa jornalística. Devem trazer novidade e originalidade, gerar repercussão, revelar importância e gravidade, registrar a opinião de todas as pessoas envolvidas e divulgar a posição de autoridades que possam trazer esclarecimentos e tomar decisões para resolver os problemas abordados. Esse processo, bem articulado, produz o sentido desejado, associando a imagem dos meios de comunicação ao local de referência para o debate público. O repórter-amador, contudo, cria o próprio critério ao eleger o que, para ele, é importante ou não, sem passar pelos filtros impostos pelo campo do jornalismo.

9 Segundo Rodríguez (1995), os estudos sociológicos que utilizam a ARS se multiplicaram a partir de 1978, sobretudo com a criação do International Network for Social Network Analysis (INSNA) e suas revistas de divulgação.
} 
ator na rede características importantes para o comportamento, percepção e atitude das unidades individuais e do sistema em seu conjunto.

Assim, na ARS os atributos dos indivíduos são secundários e as relações entre os atores são o principal, uma vez que estas explicam os processos e comportamentos sociais com base nas conexões sociais, assim como na densidade, centralidade $^{10}$ etc. Para Rodríguez, em uma investigação de redes os elementos fundamentais são: a) a escolha da unidade amostral (o objeto de estudo, ou seja, os atores da rede ou tipos de relações mais relevantes para a pesquisa), b) as formas de relação (intensidade da união entre atores ou nível de participação nas mesmas ações), c) o conteúdo relacional (relações de poder, instrumental, sentimental etc.) e d) os níveis de análise (redes egocêntricas, díades, tríades etc.).

Em uma pesquisa científica que se utiliza da ARS, o pesquisador deve ter atenção ao recolher os dados (que podem ser feitos através de ferramentas de webscrapping, como R e Netvizz, ou até questionários) e ao analisá-los (MOLINA, 2001). Após obter os elementos necessários para a ARS é fundamental seguir algumas técnicas para ordenar as informações recolhidas, as quais podem ser transformadas em gráficos e índices (SANTOS, 1996).

Em um exemplo hipotético de uma análise de fanpage ou grupo de discussão no Facebook (que pode pertencer a um repórter-amador, por exemplo), o primeiro passo da pesquisa de campo (após ter a questão de pesquisa e metodologia definida) seria definir categorias de análise do objeto empírico (quais aspectos se pretende investigar?) e o recorte temporal. Com essas decisões, seria possível por meio de softwares, como os supracitados R e Netvizz, levantar dados de redes e também gerais, como a) temas das postagens, b) tipo (vídeo, foto, link etc.), c) horário da publicação e d) quantidade de likes, comentários, reações e compartilhamentos.

Posteriormente, a análise de dados poderia ser feita por outros programas, a depender da familiaridade do pesquisador. De ARS, alguns recomendados são o Gephi e o Unicet (ALEZANDRO; NORMAN, 2005) - que possibilitam a construção de sociogramas e a obtenção de representações numéricas. As informações a serem analisadas permitiriam criar redes do objeto empírico, analisar métricas dessas redes e entender a dinâmica das postagens. Recuero (2014) tem algumas pesquisas nesse sentido, que ressaltam as contribuições da ARS para o estudo das redes sociais virtuais.

\footnotetext{
10 Além de centralidade e densidade, alguns conceitos chaves da ARS são: acessibilidade (capacidade de uma rede em permitir o acesso de uns "nós" a outros); conteúdo (tipo da relação, tais como de amizade, ajuda mútua, informação etc.); direção (sentido de uma relação), durabilidade (período de vigência de uma relação); intensidade (valor atribuído pelos atores a uma relação); frequência (número de relações em um período determinado).
} 
Figura 1 - Os elementos básicos de uma rede de interações

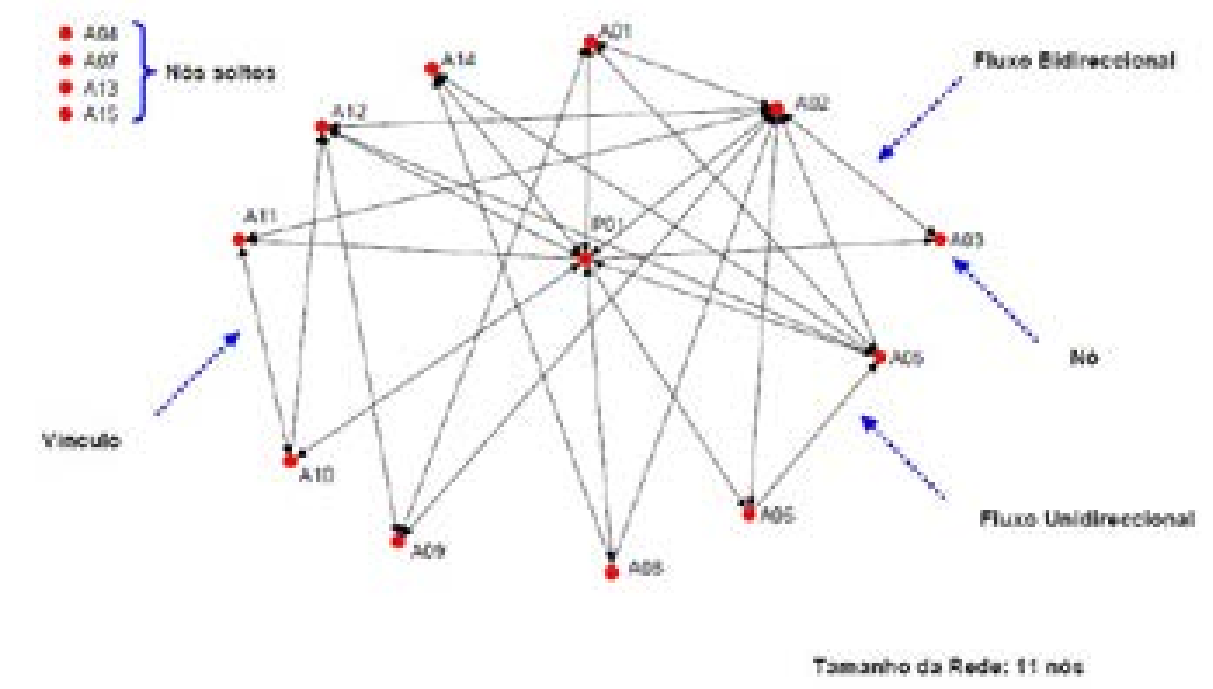

Fonte: Manual introdutório à Análise de Redes Sociais (ALEZANDRO; NORMAN, 2005). Nota: Acima, os três elementos básicos de uma rede: (I) os "nós" ou atores (onde "A" representa aluno e "P" professor), (II) os vínculos (laços estabelecidos entre atores) e (III) o fluxo da relação (que pode ser unidirecional, de apenas uma via, ou bidirecional, com reciprocidade entre os atores).

A ARS, entretanto, não resolve todos os problemas do pesquisador. Hollstein (2011) e Ferreira e Fontes (2013) ressaltam que a união de métodos qualitativos à ARS oferece ferramentas capazes de fazer frente aos desafios enfrentados na pesquisa de rede, a exemplo de elucidar a complicada relação entre agência/ estrutura e questões relativas à constituição e dinâmica de sistemas sociais.

Assim, para contribuir na interpretação dos dados da ARS, estes mais quantitativos, entrevistas semiestruturadas podem ajudar a compreender a trajetória do objeto empírico e a verificar outras categorias de análise, como motivações e características sociodemográficas (CAVALCANTI, 2016). Com as entrevistas realizadas, o pesquisador pode usar técnicas para interpretá-las, como a análise de discurso (BURITY, 2007) ou de conteúdo. Nesse sentido, a ARS pode ser aplicada para identificar as relações estabelecidas entre atores, enquanto as entrevistas para compreender e analisar essas relações.

Um exemplo é a pesquisa feita por Cavalcanti (2016). Aplicando a ARS no estudo de um grupo de repórteres-amadores no Facebook, o autor gerou um sociograma das relações entre os líderes do coletivo Direitos Urbanos/Recife (DU). O resultado foi a Figura 1, feita da seguinte maneira: solicitou-se a seis líderes do DU, escolhidos através da técnica Bola de Neve, que citassem até 15 pessoas com as quais mais se relacionassem dentro do DU; desse ponto de partida, gerou-se 
uma rede única com as redes egocentradas desses seis entrevistados. A ideia do estudo foi verificar a posição estratégica de lideranças do DU no processo de mobilização de internautas.

Figura 2 - Rede de interação dos líderes do DU

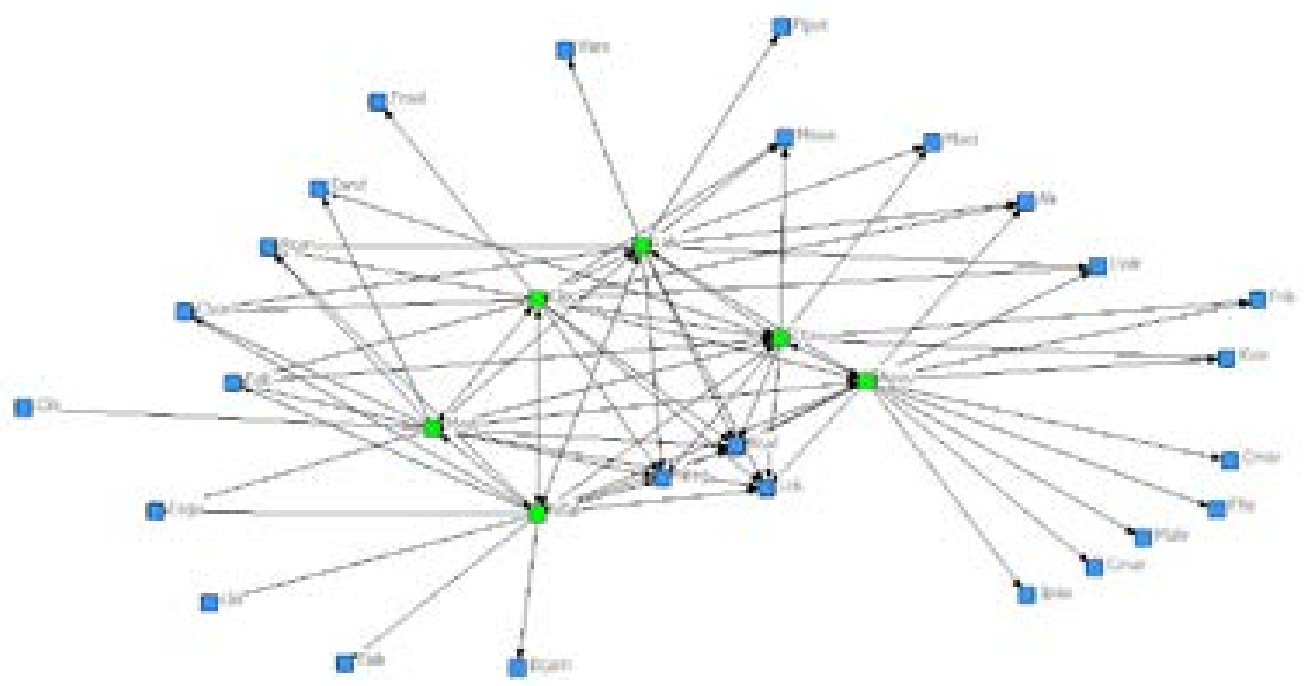

Fonte: Pesquisa de Cavalcanti (2016). Nota: Nesta rede, os “nós" verdes são os entrevistados e, os azuis, os citados por eles.

A partir da ARS, Cavalcanti verificou os atores mais citados pelos seus pares (Lalv, Apau, Nfal, Ctav, Rraf, Lcis e Nreg). Porém, o autor queria entender o porquê de essas relações existirem, o que o levou a realizar entrevistas semiestruturadas, as quais apontaram para fatores como "tempo de amizade", "condição socioeconômica" e "local de residência".

Oliveira (2015) também utilizou entrevistas semiestruturadas em sua pesquisa, avaliando a relação entre agência (ator) e estrutura (sistemas) dentro de alguns mundos sociais, como os da família, da comunidade e do trabalho. Assim, foi possível reconstruir as fases de socialização dos repórteres-amadores para se compreender como, cada um, construía inconscientemente disposições para, em seu tempo livre, motivar-se a realizar a ação de produzir notícia em espaços elaborados pelos próprios atores.

Além de entrevistas, ferramentas para capturas de dados no Facebook também podem auxiliar análises de rede. Um exemplo é o Netvizz, que permite obter, além de informações de rede, dados sobre os posts com maior "engajamento"»1 de uma

"Métrica que mensura a interação do público com as publicações na página, através de cliques, likes, comentários e compartilhamentos, cada um com peso diferente. 
fanpage. Em um exemplo meramente ilustrativo, mostraremos na Tabela 1 as cinco postagens com maior "engajamento" de um grupo político no Facebook: o Movimento Brasil Livre (MBL), que possui 2,7 milhões de seguidores. O recorte temporal selecionado no Netvizz foi aleatório: dez dias antes do julgamento de admissibilidade do impeachment de Dilma na Câmara dos Deputados (17.04.2016) e dez dias depois.

Tabela 1 - As cinco postagens com maior engajamento do MBL no impeachment

\begin{tabular}{|c|c|c|c|}
\hline Ordem & Engajamento & Tipo & Conteúdo/Descrição feita pelo grupo \\
\hline & 255.087 & Foto & $\begin{array}{c}\text { "Sim ao impeachment! Vitória do Brasil! Todos nas ruas agora para } \\
\text { comemorar!" }\end{array}$ \\
\hline & 170.012 & Foto & $\begin{array}{l}\text { "Ary Fontoura foi ao Faustão e criticou Dilma. Zé de Abreu foi ao Faustão, } \\
\text { defendeu Dilma, e apresentou o cuspe como método de diálogo. Um é } \\
\text { mito, outro é lixo" }\end{array}$ \\
\hline & 169.915 & Foto & $\begin{array}{c}\text { "GANHAMOS! O Brasil deu hoje um grande passo para a aprovação do } \\
\text { impeachment de Dilma Rousseff" }\end{array}$ \\
\hline & 156.756 & Vídeo & "Juiz Sérgio Moro, da Lava Jato, é homenageado em Nova York" \\
\hline & 155.230 & Foto & "Avenida Paulista agora" \\
\hline
\end{tabular}

Fonte: Elaborada pelos autores.

As informações da Tabela 1, por exemplo, somadas a uma análise de redes, poderiam ajudar a compreender melhor o MBL, rede com vários repórteres-amadores, por meio das pautas compartilhadas durante o processo de impeachment de Dilma. Uma hipotética pesquisa poderia aplicar a análise do conteúdo ou do discurso com as postagens do grupo (na Tabela 1 exibimos apenas as cinco com maior "engajamento" devido ao limitado espaço, mas o Netvizz mostra centenas de milhares).

\section{Considerações finais}

A partir de reflexões teórico-metodológicas, este texto discutiu mudanças no jornalismo, com a passagem do ator que não se contenta mais em apenas consumir e interagir com a grande imprensa, o cidadão-repórter, à condição de repórter-amador. Ao mapear as fases do jornalismo, vimos que a área sofreu grandes alterações nas últimas décadas, sobretudo com o desenvolvimento das NTIC. Para não ficarem para traz, tanto os meios de comunicação tradicio- 
nais (TV, rádio, jornais, revistas etc.) como os repórteres-amadores precisam se adaptar às novas mídias, que possuem características como interatividade, mobilidade e convergência.

Respondendo à pergunta proposta no início do ensaio, "quais as principais características do repórter-amador e como podemos estudá-lo?", apontamos que, entre outras coisas: o repórter-amador não recebe remuneração; dedica o tempo livre e de lazer a práticas jornalísticas; entra e sai do jornalismo a qualquer momento; não tem método de apuração de informação; não precisa frequentar nenhum curso universitário para ser repórter-amador; vincula essas práticas ao gosto de ler, de se informar etc.; e não quer se submeter ao controle editorial da empresa de comunicação para que possa ver publicada a notícia que criticou ou sugeriu.

Em relação a como estudar o repórter-amador, mostramos um caminho possível: na era do big data, a ARS ajuda a visualizar a teia de relações desses atores na web e o conteúdo das postagens, enquanto abordagens como entrevistas semiestruturadas (ou análise documental, netnográfica etc.), contribuem para interpretar aspectos como a trajetória desses atores e as suas motivações.

Com o acesso à internet e às novas mídias crescendo em todo mundo, novos campos de estudo passam a fazer parte do jornalismo, que se torna cada vez mais multidisciplinar, aperfeiçoando o diálogo com áreas como design, marketing, administração, tecnologia da informação etc. Estudar o repórter-amador é estar atento a essas mudanças na comunicação, investigando atores que vêm aumentando em termos de volume e ocupando paulatinamente mais espaço como fonte de informação da sociedade.

Com isso, podemos afirmar ainda que as disposições para o agir ativamente no jornalismo não são, entre esses cidadãos, simples vontades e preferências. Querer explicar, com exatidão, todas as disposições internas que fazem com que os atores, de uma maneira geral, desejem realizar esse jogo do agir ativamente, poderia ser entendido como uma pretensão desmedida. Isso porque as pistas levantadas aqui são pontos que não se esgotam.

Outros pesquisadores podem partir delas e ir além. Certamente existem mais questões importantes a serem consideradas, tanto quanto diferentes tendências a ações que levam, em última instância, o indivíduo a se sentir motivado a ser produtor de notícia. Tudo, no entanto, dependerá do olhar de quem está estudando as trajetórias, os contextos e as relações sociais dos atores. 


\section{Referências}

AMARAL, Luiz. Jornalismo: matéria de primeira página. Rio de Janeiro: Tempo brasileiro, 1997.

ANDERSON, Chris. A cauda longa. Rio de Janeiro: Editora Campus, 2006.

BECKER, Howard S. Mundos artísticos e tipos sociais. In: VELHO, Gilberto (org.). Arte e sociedade: ensaios de sociologia da arte. Rio de Janeiro: Zahar Editores, 1977. p. 09-25.

BELOCHIO, Vivian; MIELNICZUCK, Luciana. O jornalismo digital e as estratégias de colaboração: sinais da des-re-territorialização. In: STASIAK, Daiana; SANTI, Vilso Junior (org.). Estratégias e identidades midiáticas: matizes da comunicação contemporânea. Porto Alegre: EdiPUCRS, 2011. p. 57-75. https://doi.org/10.5007/1984-6924.2009v6n2p203

BRIGGS, Mark. Jornalismo 2.0: como sobreviver e prosperar - Um guia de cultura digital na era da informação. College Park: J-Lab e Knight Citizen News Network, 2007.

BURITY, Joanildo A. Teoria do discurso e análise do discurso: sobre política e método. In: WEBER, Silke; LEITHAUSER, Thomas (org.). Métodos qualitativos nas ciências sociais e na prática sociais. Recife: Editora da UFPE, 2007. p. 72-83.

CASTELLS, Manuel. Redes de indignação e esperança. Rio de Janeiro: Zahar editora, 2013. https://doi.org/10.1590/s0104-71832015000200019

CASTRO, Paulo César. Jornalismo participativo e midiatização da recepção: a domesticação dos leitores na seção "Eu-repórter" do Globo Online. IX ENCONTRO NACIONAL DE PESQUISADORES EM JORNALISMO - SBPJOR. Anais eletrônicos... Rio de Janeiro, ECO - Universidade Federal do Rio de Janeiro, 03 nov. 2011. https://doi.org/10.5753/ ersirj.2018.4649

CAVALCANTI, Davi Barboza. Redes sociais virtuais como instrumentos de mobilização política: uma análise do grupo "Direitos Urbanos/Recife" no Facebook. 2016. 144 f. Dissertação (Mestrado em Sociologia) - Programa de Pós-Graduação em Sociologia, UFPE, Recife, 2016. Disponível em: http://repositorio.ufpe.br/handle/123456789/17781. Acesso em: 24 mar. 2018. https://doi.org/10.22478/ufpb.1981-0695.2018v13n1.39003

DONK et al. (eds.). Cyberprotest - New media, citizens and social movements. London/ New York: Routledge, 2004. https://doi.org/10.4324/9780203644225

ERBOLATO, Mário. Técnicas de codificação em jornalismo. São Paulo: Ática, 2003.

FERRARI, Pollyana (org.). Hipertexto, hipermídia: as novas ferramentas da comunicação digital. São Paulo: Contexto, 2007.

FERREIRA, Jonatas; FONTES, Breno. Ágora eletrônica: algumas reflexões teórico-metodológicas. Estudos de Sociologia, Recife, v. 2, n. 19, 2013. Disponível em: http:// 
www.revista.ufpe.br/revsocio/index.php/revista/article/view/405/331. Acesso em: 14 abr. 2018.

GARCIA, Luiz (org.). O Globo: manual de redação e estilo. São Paulo: Globo, 1998.

GARCÍA DE MADARIAGA MIRANDA, José María. El periodismo en el siglo XXI: una profesión en crisis ante la digitalización. Madrid: Editorial Dykinson, SL, 2008. https:// doi.org/10.35985/9789585522060.3

GILLMOR, Dan. Nós, os media. Lisboa: Presença, 2005.

G1. Robert Mugabe renuncia à presidência do Zimbábue após 37 anos no poder. Mundo, 21 nov. 2017. Disponível em: https://g1.globo.com/mundo/noticia/mugabe-renuncia. ghtml. Acesso em: 20 mar. 2018.

HOLLSTEIN, Bettina. Qualitative approaches. In: SCOTT John (ed.). Sage handbook of social network analysis. London/New Delhi: Sage Publications Ltd., 2011. p. 404-416. https://doi.org/10.4135/9781446294413.n27

JENKINS, Henry. A cultura da convergência. São Paulo: Aleph, 2008.

KOTLER, Philip; KARTAJAYA, Hermawan; SERIAWAN, Iwan. Marketing 4.0 - do tradicional ao digital. Tradução de Ivo Korytowski. Rio de Janeiro: Sextante, 2017.

LAGE, Nilson. A reportagem: teoria e técnica de entrevista e pesquisa jornalística. Rio de Janeiro: Record, 2002.

LAHIRE, Bernard. O homem plural. Petrópolis, RJ: Vozes, 2002.

LAHIRE, Bernard. Retratos sociológicos: disposições e variações individuais. Porto Alegre: Artmed, 2004.

LAHIRE, Bernard. A cultura dos indivíduos. Porto Alegre: Artmed, 2006.

LAHIRE, Bernard. Por uma sociologia disposicionalista e contextualista da ação. In: JUNQUEIRA, L. (org.). Cultura e classes sociais na perspectiva disposicionalista. Recife: Editora da UFPE, p. 17-36, 2010.

LARA, Tíscar. Periodismo ciudadano. ¿Qué tiene de peridismo? ¿Qué tiene de ciudadano?. Madri: UIP, maio de 2009, s/p. Disponível em: http//www.slideshare.net/tiscar/ periodismociudadano-1481066. Acesso em: 07 abr. 2018.

LIMA SOBRINHO, Barbosa. O industrialismo na imprensa. In: LIMA SOBRINHO, Barbosa. O problema da imprensa [1923], capítulo transcrito da 2. ed. São Paulo: Edusp, p. 2934, 1988.

MARCONDES FILHO, Ciro. Comunicação e jornalismo. A saga dos cães perdidos. São Paulo: Hacker Editores, 2002. 
MELO, Patrícia Bandeira de. Sujeito sem voz: agenda e discurso sobre o índio na mídia em Pernambuco. Recife: UFPE, 2003. Mimeo.

MELO, Patrícia Bandeira de. Histórias que a mídia conta: o discurso sobre o crime violento e o trauma cultural do medo. Recife: Editora da UFPE, 2010.

MESQUITA, Giovana. Jornalismo participativo e as novas relações entre imprensa e audiência na produção de notícia. XIII CONGRESSO DE CIÊNCIAS DA COMUNICAÇÃO NA REGIÃO NORDESTE. Anais... Campina Grande (PB): Intercom Regional, junho de 2010.

MOLINA, Jose Luis. El análisis de redes sociales: uma introducción. Barcelona: Bellaterra, 2001.

MORETZSOHN, Sylvia. Pensando contra os fatos - Jornalismo e cotidiano: do senso comum ao senso crítico. Rio de Janeiro: Revan, 2007.

MOYO, Last. Repression, propaganda, and digital resistance: new media and democracy in Zimbabwe. In: MUDHAI, Okoth Fred; TETTEY, Wisdom J., BANDA, Fackson (eds.). African media and the digital public sphere. New York: Palgrave Macmillan, p. 57-71, 2009. https://doi.org/10.1057/9780230621756 4

OLIVEIRA, Sheila Borges de. 0 repórter-amador: uma análise das disposições sociais motivadoras das práticas jornalísticas do cidadão comum. Recife: Editora Cepe, 2015.

PRIMO, Alex Fernando Teixeira. Transformações no jornalismo em rede: sobre pessoas comuns, jornalistas e organizações; blogs, twitter, facebook e flipboard. IX ENCONTRO NACIONAL DE PESQUISADORES EM JORNALISMO - SBPJOR. Anais eletrônicos... Rio de Janeiro, ECO- Universidade Federal do Rio de Janeiro, 03 nov. 2011. https://doi. org/10.5753/ersirj.2018.4649

RECUERO, Raquel. Redes sociais na internet, difusão de informação e jornalismo: elementos para discussão. In: SOSTER, Demétrio de Azeredo; FIRMINO, Fernando (org.). Metamorfoses jornalísticas 2: a reconfiguração da forma. Santa Cruz do Sul: EDUNISC, 2009. p. 39-55.

RECUERO, Raquel. Contribuições da análise de redes sociais para o estudo das redes sociais na internet: o caso da hashtag \#Tamojuntodilma e \#CalaabocaDilma. Revista Fronteiras - Estudos Midiáticos, São Leopoldo, v. 16, n. 2, p. 60-77, maio/agosto de 2014. https://doi.org/10.4013/fem.2014.162.01

RODRÍGUEZ, Josep A. Análisis estructural y de redes. Cuadernos metodológicos, Madri, n. $16,1995$.

SANTOS, Rogério. Jornalistas e fontes de informação: a sua relação na perspectiva da sociologia do jornalismo. Coimbra: Edições Minerva Coimbra, 2003.

SBARAI, Rafael. Minha notícia, IReport e OhmyNews: modelos de cooperação ou colaboração no jornalismo digital? In: LIMA JUNIOR, Walter Teixeira (org.). Comunicação, 
tecnologia e cultura de rede. São Paulo: Momento Editoral, 2011. p. 12-39. Disponível em: http://www.livroteccred.blogspot.com. Acesso em: 16 maio 2018.

SOARES, Marcelo; SÁ, Nelson de. Jornalismo domina rede social durante protestos pelo país. Poder, Folha de S. Paulo, São Paulo, 4 jul. 2013. Disponível em: http://www1.folha.uol. com.br/poder/2013/07/1305911-jornalismo-domina-rede-social-durante-protestos-pelo-pais.shtml. Acesso em: 23 fev. 2018. https://doi.org/10.20287/ec.n26.v2.a10

SOSTER, Demétrio de Azeredo. Modelo para análise do jornalismo midiatizado. In: SOSTER, Demétrio de Azeredo; FIRMINO, Fernando (org.). Metamorfoses jornalísticas 2: a reconfiguração da forma. Santa Cruz do Sul: EDUNISC, p. 120-140, 2009. https:// doi.org/10.17058/rzm.v3i1.6254

VIZEU, Alfredo (org.). A sociedade do telejornalismo. Petrópolis: Vozes, 2008.

VIZEU, Alfredo; ROCHA, Heitor; MESQUITA, Giovana. Nem jornalista, nem somente audiência: o cidadão como coprodutor da notícia, novos desafios para o Jornalismo. Revista ECOPÓS, Dossiê: cidades midiáticas, Rio de Janeiro, v. 14, n. 1., p. 291-302, 2011. Disponível em: https://revistas.ufrj.br/index.php/eco pos/ article/view/923/863. Acesso em: 2 abr. 2018.

\section{Dados dos autores:}

Davi Barboza Cavalcanti - davi.barboza@hotmail.com

Professor do Centro Universitário Brasileiro (Unibra). Doutorando em Ciência Política e Mestre em Sociologia pela UFPE.

\section{Endereço do autor:}

Universidade Federal de Pernambuco, Centro de Filosofia e Ciências Humanas Rua Acadêmico Hélio Ramos, s/n - 14 ${ }^{\circ}$ andar, Cidade Universitária, 50.670-901 - Recife (PE) - Brasil

\section{Sheila Borges de Oliveira - sheilaborges12@gmail.com}

Professora adjunta do Núcleo de Design e Comunicação da Universidade Federal de Pernambuco. Doutora em Sociologia e Mestra em Comunicação pela UFPE.

\section{Endereço da autora:}

Universidade Federal de Pernambuco, Centro de Artes e Comunicação Av. da Arquitetura, s/n, Campus Universitário, 50.740-550 - Recife (PE) - Brasil 